\title{
Práctica Jurídica de la Salud Pública
}

\section{Agustín Carignani}

Abogado, Diplomado en Instituciones Profundizadas del Derecho Laboral y en Derecho de la Salud. Investigador colaborador en Programa de Direito Sanitário de la Fundação Oswaldo Cruz (Prodisa / Fiocruz), en Brasília, Brasil.

El libro Práctica Jurídica de la Salud Pública - Volumen IV es una obra editada por el Ministerio de Salud de la Provincia de Córdoba, continuadora y actualizadora de ediciones anteriores que comenzaron en el año 2008 con su primer volumen, realizado en el marco del Programa de Desarrollo de Actividades de Investigación en la Práctica Institucional, Derecho y Administración Sanitaria 2008-2011 (PRODAl), obra que cuenta con un Comité de Referato integrado por juristas, científicos y académicos de nota en la materia y una bibliografía doctrinaria y legislativa de los temas más actuales vinculados con el derecho a la salud pública provincial y nacional. Organizada por los Abogados Ortega, Zavaley, Robledo y Senesi, del Ministerio de Salud de la Provincia de Córdoba, ha llegado a ubicarse en las bibliotecas legislativas, Universidades, máximos tribunales provinciales, organismos internacionales, entidades científicas del Derecho y la Medicina.

En su primer apartado, trata el tema relacionado con los convenios como instrumentos de tutela del derecho a la salud que facilitan la obtención de los objetivos públicos de manera eficaz, eficiente y equitativa; entendiendo esta institución como vínculo más que como prestación, permitiendo, de esta manera, armonizar compromisos para satisfacer intereses comunes, siendo utilizados en un sinnúmero de aspectos centrales de la gestión pública. En el siguiente capítulo, se realiza una compilación de las normas basales del sistema de evaluación ética de la Investigación Biomédica en la Provincia de Córdoba, donde, en ese contexto, también se establece el marco normativo del poder de policía sanitaria y el referido a las profesiones como materia de regulación reservada a las provincias y, consecuentemente, no delegadas a la Nación. Otra cuestión estudiada es el consentimiento informado desde la bioética de los 
derechos humanos y los derechos de los pacientes, donde se analiza el consentimiento informado desde su dimensión conceptual, la construcción de la doctrina bajo la mirada de la Bioética de los Derechos Humanos y, finalmente, su interpretación en el derecho interno.

Se lleva adelante también un análisis de los lineamientos básicos del Poder de Policía en materia sanitaria en la Provincia de Córdoba, estableciendo el alcance de la noción "poder de policía" y su diferencia con la noción "policía". Se pone de relevancia el ámbito de aplicación de este Poder de Policía en la Provincia de Córdoba.

Otro de los temas abordados es el relacionado a los derechos fundamentales de los ancianos, donde se enfatiza el rol del Estado desde sus tres órbitas de gobierno, en procura del bienestar de las personas en la tercera edad y la responsabilidad social de acuerdo con el Principio de Subsidiaridad Federal. También se encara la inclusión de la salud ambiental en el marco del ordenamiento jurídico argentino, desde 1972 hasta su estatus legal luego de la reforma constitucional de 1994, poniendo de relevancia la estricta vinculación de la salud ambiental con la salud humana y la calidad de vida humana.

Se aborda también la institución del "Recurso Humano Crítico", problemática que fue considerada por la Organización Panamericana de la Salud (OPS) y la Organización Mundial de la Salud (OMS) como herramienta para combatir la problemática de la insuficiente producción de ciertas profesiones $u$ oferta de determinadas actividades del ámbito de la salud.

Otra de las cuestiones encaradas en la obra reseñada es la regulación del tabaquismo y como ésta fue mudando con el transcurso del tiempo y la concientización de los efectos adversos que el consumo del mismo produce en la salud de las personas. Se realiza también un análisis constitucional, en ámbito provincial, nacional e internacional en el marco del Mercosur, de la salud como un bien social y, como tal, de las normas que garantizan el acceso igualitario a la salud y las herramientas para resguardar tal derecho.

Otra de las cuestiones sumamente interesantes que se encaran son las emergencias sanitarias reconocida como una institución del Estado de Derecho, dispuesta como una garantía jurídica para preservar un derecho fundamental de 
los ciudadanos frente a situaciones de crisis, generando reglas acordes con el estado de excepcionalidad, siendo así, un modo de potenciar las atribuciones de la autoridad pública para la mayor defensa de los derechos y garantías constitucionales.

También se analiza un caso jurisdiccional excepcional donde se solicita un tratamiento de fecundación in vitro y se analizan las decisiones jurisprudenciales atinentes al pedido, en el marco legal existente y donde el juzgador prioriza el derecho a la vida a través de una solución atípica, excepcional y pretoriana. Se plantea, asimismo, la situación de la atención en salud de los hospitales públicos de la Provincia de Córdoba y los derechos del paciente, en el marco de lo normado por la Carta del Ciudadano (Ley no 8.835) y la Constitución Provincial.

Gran destaque tiene el artículo en el cual se analiza pormenorizadamente el ejercicio legítimo de las profesiones de la salud, donde se realiza un estudio analítico de las reglamentaciones de la profesiones, obligaciones y derechos, tanto de los profesionales argentinos como de aquellos extranjeros que revalidan su actividad, la matriculación y reglamentación de las actividades; el rol de los colegios profesionales; las residencias en salud como asimismo de las especialidades.

Se hace una referencia también a los procesos de elaboración de los convenios suscriptos con Estados o personas jurídicas extranjeras, donde se desarrollan las etapas pre y post suscripción y se resalta la importancia práctica de dichas etapas, como asimismo de los contratos. Dicha obra también dedica un apartado específicamente a los convenios suscriptos por el Ministerio de Salud de la Provincia de Córdoba, indicando los procedimientos tendientes a la organización y sistematización con la finalidad de formalización y seguimiento de los mismos haciendo alusión a modo ejemplificativo de alguno de ellos.

Finalmente, se acompaña un repertorio de dictámenes e informes de la Dirección de Jurisdicción de Asuntos Legales del Ministerio de Salud que, como se anuncia en la reflexión inicial, son producto de la aplicación práctica de normas y principios inherentes al campo sanitario. 
El libro se dirige a abogados, gestores de servicios de salud, legisladores, consultores legislativos, profesores e investigadores de Derecho Sanitario que encontrarán ahí materias de interés para sus prácticas profesionales.

ORTEGA, José Emilio; ZAVALEY, Rodolfo Nicolás; ROBLEDO, Frederico; SENESI, Franco Miguel (Org.) Práctica Jurídica de la Salud Pública, vol. 4. Colección: Administración Sanitaria. Córdoba : Editorial Ministerio de Salud de la Provincia de Córdoba, 2011. ISBN: 978-950-840-016-1.

www.advocatus@fibertel.com.ar 